\title{
STUDIES ON THE MECHANISM OF THE EXCITATION- CONTRACTION COUPLING IN CARDIAC MUSCLE, WITH SPECIAL REFERENCE TO THE CAFFEINE-CONTRACTURE
}

\author{
Keishi SuzukI* \\ Department of Physiology, Sapporo Medical College
}

The nature of the process or processes which link the electrical and mechanical events in muscle activity remains unknown. Concerning the excitationcontraction coupling ( $\mathrm{E}-\mathrm{C}$ coupling $)^{1}$, many workers have considered that the first step of the E-C coupling is the depolarization occurs in the membrane of the cell $1^{2,3,4,5)}$. Although subsequent steps of the processes have been proposed by several workers ${ }^{6,7)}$, as yet, no actual evidence has been presented.

According to the recent studies on the contracture of skeletal muscle induced by caffeine, this agent seems to initiate a process which may be involved in the $\mathrm{E}-\mathrm{C}$ coupling. This process is not mediated by change in the resting potential ${ }^{8,9)}$ or in the ionic permeability of the muscle membrane ${ }^{9}$.

The analysis of the mechanism of the E-C coupling in the cardiac muscle seems to be important not only from the physiological standpoint but also from the clinical view point. It may also serve elucidating the regulating mechanism of activity of heart by autonomic nervous system and the action of cardiac glycocides.

In the present study, the effects of caffeine on the mechanical and electrical properties of cardiac ventricular muscle cell were investigated in detail. A special attention was paid to the conditions required to induce the caffeinecontracture.

\section{METHODS}

The material and the solutions used in the present experiment were prepared as follows: 1) Cardiac ventricular strip: Strips were dissected from cardiac ventricle of frog (Rana nigromaculata) by the method described by Kotowski et al ${ }^{10)}$. The size of strip was $1.5 \mathrm{~mm}$ in width and $10-12 \mathrm{~mm}$ in length. 2) Ringer solution: The composition of the solution was as follows: $\mathrm{NaCl} 122 \mathrm{mM}, \mathrm{CaCl}_{2} 1.3 \mathrm{mM}, \mathrm{KH}_{2} \mathrm{PO}_{4} 2.0 \mathrm{mM}$, $\mathrm{NaHCO}_{3} 1.3 \mathrm{mM}$. pH of the solution was adjusted to $7.0-7.2$ by addition of $\mathrm{M} / 8$ $\mathrm{NaHCO}_{3}$. 3) K-Ringer solution: $\mathrm{NaCl}$ in Ringer solution was replaced isosmotically by

Received for publication November 24, 1961.

* 鈴木啓司 
equal volume parts of $122 \mathrm{mM} \mathrm{KCl.} \mathrm{50 \%} \mathrm{K-Ringer} \mathrm{solution:} 61 \mathrm{mM} \mathrm{KCl}$ was substituted for a half amount of $\mathrm{NaCl}$ contained in Ringer solution. 4) Choline chloride-Ringer solution: Choline chloride was substituted for all $\mathrm{NaCl}$ in Ringer solution, so that the concentration of choline chloride was $122 \mathrm{mM}$. 5) Nonelectrolyte-Ringer solutions: One of the nonelectrolytes, such as sucrose, glucose or glycerine, was substituted for $\mathrm{NaCl}$ in Ringer solution. Thus, the solutions prepared were osmotically equivalent to the Ringer solution, that is, the solution had $244 \mathrm{mM}$ of each nonelectrolyte ${ }^{11)}$. 6) Stock solutions of chelating agents: As the stock solutions, ethylendiamintetraacetic acid (EDTA), sodium citrate and sodium oxalate were dissolved in deionized water respectively. The concentration of the first two solutions was $100 \mathrm{mM}$ and that of the last one was $50 \mathrm{mM}$. When necessary, these stock solutions were mixed with the various Ringer solutions to obtain the desired concentrations of the chelating agents. 7) Caffeine solutions: 5 to $50 \mathrm{mM}$ caffeine solutions were prepared by dissolving caffeine monohydrate (Kanto Chem. Co.) in the various Ringer solutions.

Experimental apparatus and procedures.

1. Recording of mechanical response: The tension of the strip was measured with mechano-electronic transducer (RCA-5734). As schematized in FIG. 1, the strip was immersed in experimental solution filled in a $10 \mathrm{ml}$ chamber. With use of silk threads,

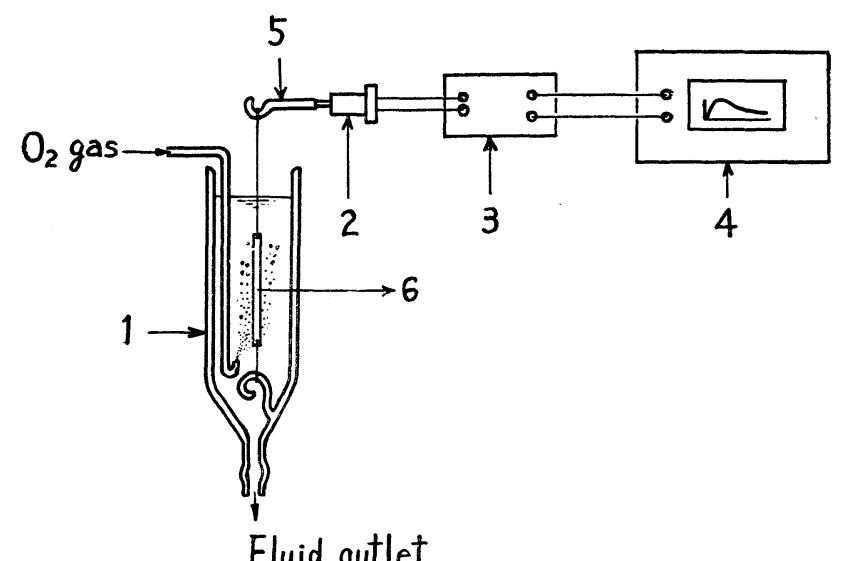

FIG. 1. Diagram showing apparatus for isometric recording. 1. Chamber for suspending cardiac ventricle strip. 2. Mechano-electronic transducer (RCA-5734). 3. D. C. amplifier. 4. Ink-writing electromagnetic oscillograph. 5. The glass lever connected to the mechano-electronic transducer. 6. Muscle strip.

one end of the strip was fixed to the hook of the chamber and the other end was fixed to the hook of the glass lever of $15 \mathrm{~mm}$ length which was connected with the mechano-electronic transducer. The change in the tension of the strip was recorded by means of an ink-writing electromagnetic oscillograph. The isotonic contraction of the strip was recorded with a kymograph.

2. Recording of the electrical response: The action potentials were recorded in the samples different from those used for the recording of the mechanical response. The strip was immersed horizontally in a chamber containing $7 \mathrm{ml}$ of the experimental 
solution, in which the both ends of the strip were fixed with silver needles. With the intracellular microelectrode technique, the transmembrane potentials of the cardiac ventricular cells were led to d. c. amplifier set in the cathode ray oscilloscope through a cathode follower preamplifier. The suspension electrode ${ }^{12}$ was used as a recording electrode. The electric resistance of the microelectrodes used were 10 to 40 megohm. With the aid of both a micromanipulator and a binocular microscope, the microelectrode was inserted into the cardiac ventricular cell.

3. Stimulation: The strip was stimulated along its longer direction with a rectangular pulse $(20 \mathrm{~V} / \mathrm{cm}, 3 \mathrm{msec}$. in duration) generated from an electronic stimulator through a pair of $\mathrm{Ag}-\mathrm{AgCl}$ electrodes.

4. Exchanging the experimental solution: In the recording of the electrical response, a special caution was made to exchange the experimental solution to avoid shaking of electrode in the cardiac cell. A new solution was poured into the chamber with a $20 \mathrm{ml}$ injection syringe and at the same time the solution which had been used was ejected from the chamber with another syringe ${ }^{13}$. In the recording of mechanical response, the solution used first was poured out from the chamber, then a new solution was filled in it.

5. Experimental condition: All experiments were carried out in the oxygenated solutions at room temperature $\left(17^{\circ} \mathrm{C}-23^{\circ} \mathrm{C}\right)$ and were performed from September in 1960 to March in 1961.

\section{EXPERIMENTAL RESULTS}

1. Effects of caffeine on the automaticity and contractility of the strip. As shown in FIG. 2A, caffeine increased the grade in the automatic contraction at the low concentration (5 to $10 \mathrm{mM}$ caffeine in Ringer solution). As the concentration of caffeine increased, the automatic contraction of the strip decreased slightly and an arhythmia appeared. At the higher concentration of caffeine $(50 \mathrm{mM})$, the automaticity of the strip disappeared rapidly. However, the strip thus treated responded to the electrical stimuli and the automaticity was recovered when bathing solution was replaced by the normal Ringer solution again.

Under the conditions aforementioned, the strip did not show any indication of contracture by caffeine.

2. Effects of caffeine on the resting and action potentials of the cardiac ventricular cell. The changes in the resting and action potentials of ventricular cells after the addition of $50 \mathrm{mM}$ caffeine are illustrated in FIG. 3. The action potentials recorded are shown in FIG. 4. In caffeine of such a high concentration, the resting potential was lowered with the lapse of time and after 20 minutes it decreased by about $10 \mathrm{mV}$. But the magnitude of the resting potential increased again to the initial value when the bathing solution was replaced by the normal Ringer solution (FIG. 3).

The duration of the plateau of the action potential tended to shorten in the solution containing caffeine. In this case, however, the amplitude of the action potential was not undergone appreciable change. Furthermore, the change in the shape of plateau was recovered to normal when the bathing 
A.

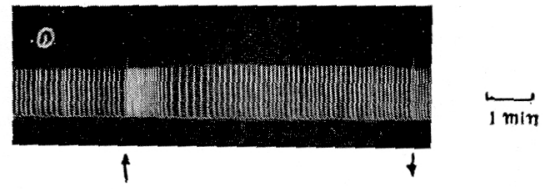

2.

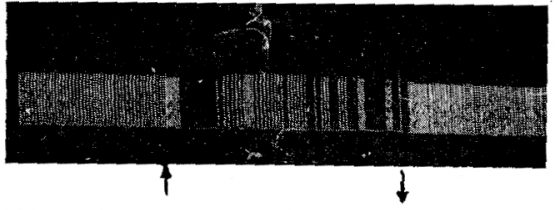

3.

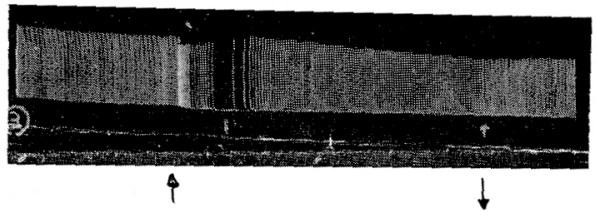

B.
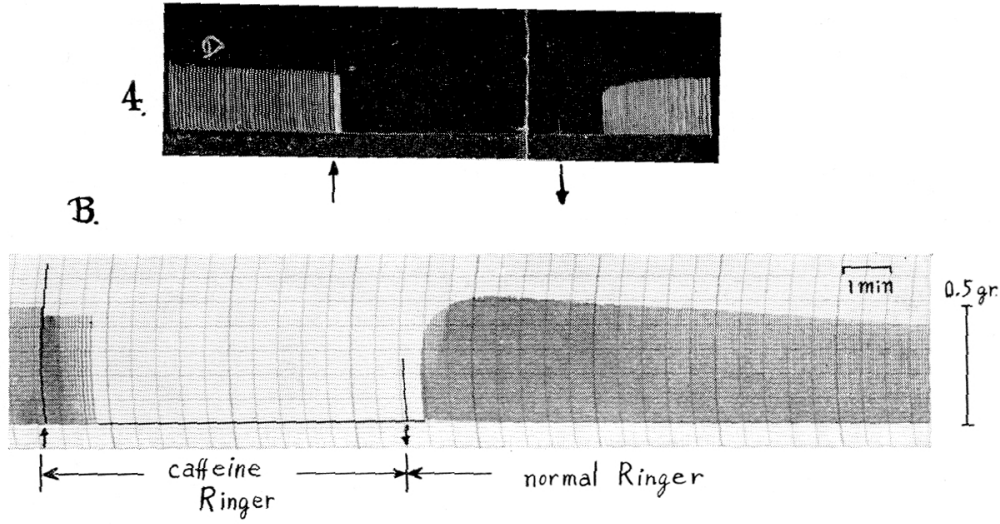

FIG. 2. Effects of caffeine on both automaticity and contractility of cardiac ventricle strip in normal Ringer solution $\left(22^{\circ} \mathrm{C}\right)$. Arrow $\uparrow$ indicates the addition of caffeine; arrow $\downarrow$ indicates transference of the strip from caffeine-Ringer solution to normal Ringer solution. A. Isotonic recordings. 1. $10 \mathrm{mM}$ caffeine; $2.20 \mathrm{mM}$ caffeine; $3.30 \mathrm{mM}$ caffeine; $4.50 \mathrm{mM}$ caffeine. B. Isometric recording in $50 \mathrm{mM}$ caffeine.

solution was replaced by the Ringer solution. This apparently indicates that the effect of caffeine on the cardiac ventricular cell is reversible even when the concentration of caffeine is as high as $50 \mathrm{mM}$. This means an important difference between the cardiac ventricular muscle and the skeletal muscle.

When the strip was immersed in the Ringer solution containing the high concentration of caffeine for a long period (more than 1 hour), the contraction by an electrical stimulus was weakened and limited in some portion of the strip. The action potential recorded in this portion showed the shorter dura- 


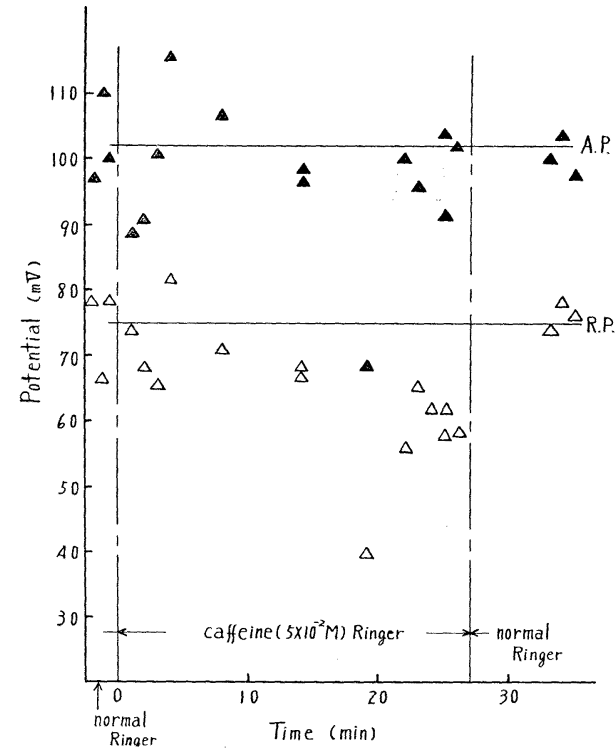

Fig. 3. Effects of $50 \mathrm{mM}$ caffeine on both resting and action potentials of the cardiac ventricular cells in normal Ringer solution $\left(20^{\circ} \mathrm{C}\right)$. The site, where a microelectrode was inserted, was not always the same in each recording, but the attention was paid to insert the electrode into the same site as possible. Abscissa, time after addition of caffeine; ordinate, transmembrane potential difference in $\mathrm{mM}$; solid triangle, action potential (up to peak); open triangle, resting potential; A.P., the average of three action potentials of the cells in normal Ringer solution; R. P., the average of three resting potentials of the cells in normal Ringer solution.

tion of the plateau; it seemed as if only the spike component remained.

3. Effects of the caffeine on the K-depolarized strip. When the strip was immersed in isotonic K-Ringer solution, the magnitude of its resting potential amounted to about $10 \mathrm{mV}$ (FIG. 5). In K-Ringer solution, a transitory K-contracture of the strip was induced, while the automaticity and the excitability disappeared (upper record in FIG. 6). Lower record in FIG. 6 shows a contracture of the strip which was immersed in K-Ringer solution and then transfered to K-Ringer solution containing $50 \mathrm{mM}$ caffeine. This contracture*) appeared as soon as the strip was immersed in the caffeine solution. The tension of the strip reached the maximum value at 2 to 3 minutes after immersion and spontaneously returned to the initial value after 20 minutes. The transmembrane potential of the strip immersed in K-Ringer solution did not change even in the presence of caffeine (FIG. 5-C, D, E). When the K-Ringer solution was replaced by the normal Ringer solution, the automaticity and resting and action potentials of the strip were recovered to the normal state. Thus the caffeine-contracture described above may not be "Schädigungskontraktur" defined by FLECKENSTEIN ${ }^{14)}$, but may be an ordinary contracture induced by caffeine as 'excitant'.

The contracture has some relation to the concentration of caffeine. The lowest concentration of caffeine to induce contracture of the strip was about

*) It is apparent that the contracture was not caused by the hypertonicity of the experimental solution resulted from the addition of caffeine, because no contracture appeared both in $50 \mathrm{mM}$ caffeine-Ringer solution and in $100 \mathrm{mM}$ sucrose-K-Ringer solution, which are considered slightly hypertonic. 

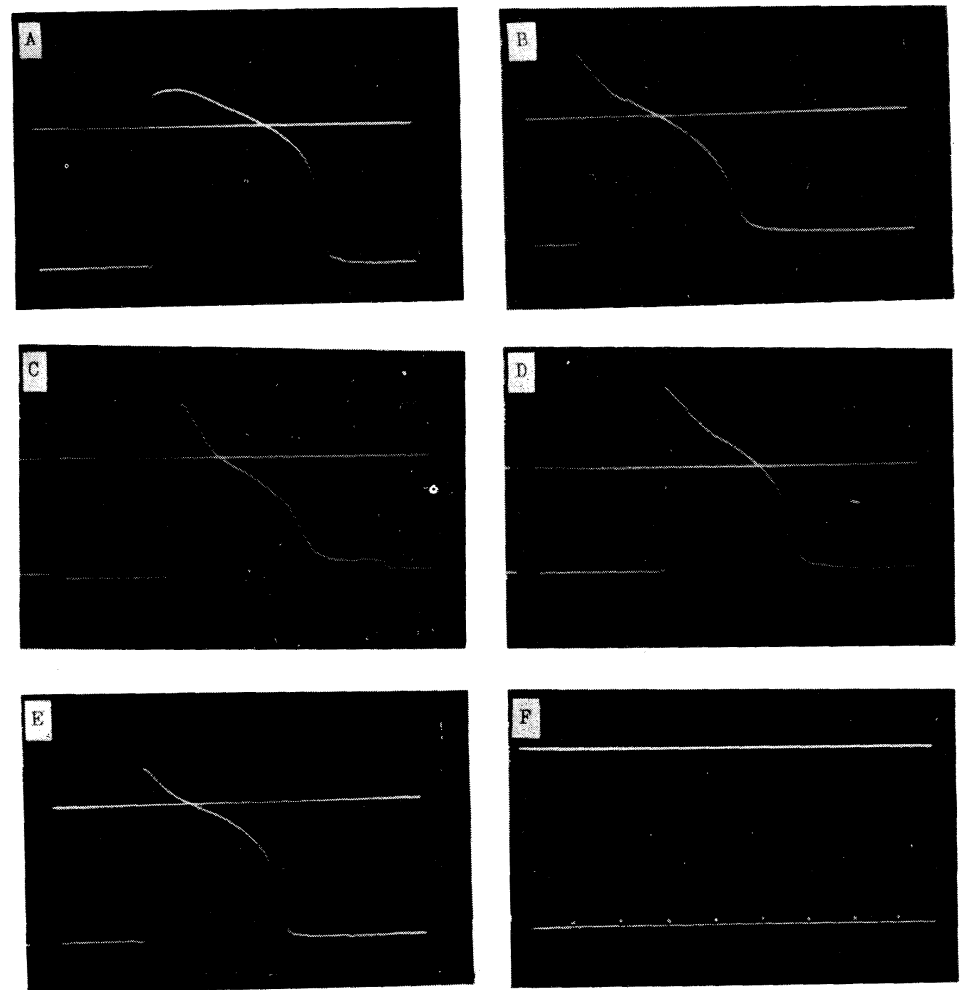

Fig. 4. Action and resting potentials of the cardiac ventricular cells recorded with microelectrode at various times after the immersion in Ringer solution containing $50 \mathrm{mM}$ caffeine $\left(20^{\circ} \mathrm{C}\right)$. A. Ringer solution. B. 8 min. after immersion in caffeine. C. $14 \mathrm{~min}$. after immersion in caffeine. D. $24 \mathrm{~min}$. after immersion in caffeine. E. $7 \mathrm{~min}$. after replacing caffeine by normal Ringer solution. F. $3 \mathrm{cps}$; distance between the two lines shows $100 \mathrm{mV}$.

$10 \mathrm{mM}$. As the concentration of caffeine increased, the contracture became more remarkable.

4. Effects of caffeine on the cardiac ventricular cell in the nonelectrolyte-Ringer solution. In the above-mentioned experiment, a question whether the membrane depolarization of the ventricular cell is indispensable for the contracture induced by caffeine was left unsolved. To examine this problem the following experiments were carried out by using sucrose-Ringer solution which is known to prevent the depolarization of the cell membrane. ${ }^{32}$ The automaticity of the strip disappeared in this solution as observed in the experiment with K-Ringer solution, while by electrical stimuli the strip showed more remarkable contraction in sucrose-Ringer solution than in normal Ringer solution. This coincides with the results reported by DALY ${ }^{15)}$ and NiEDERGERKE and LÚTTGAU ${ }^{16)}$. Furthermore, when the sucrose-Ringer solution was replaced by $50 \mathrm{mM}$ caffeine- 

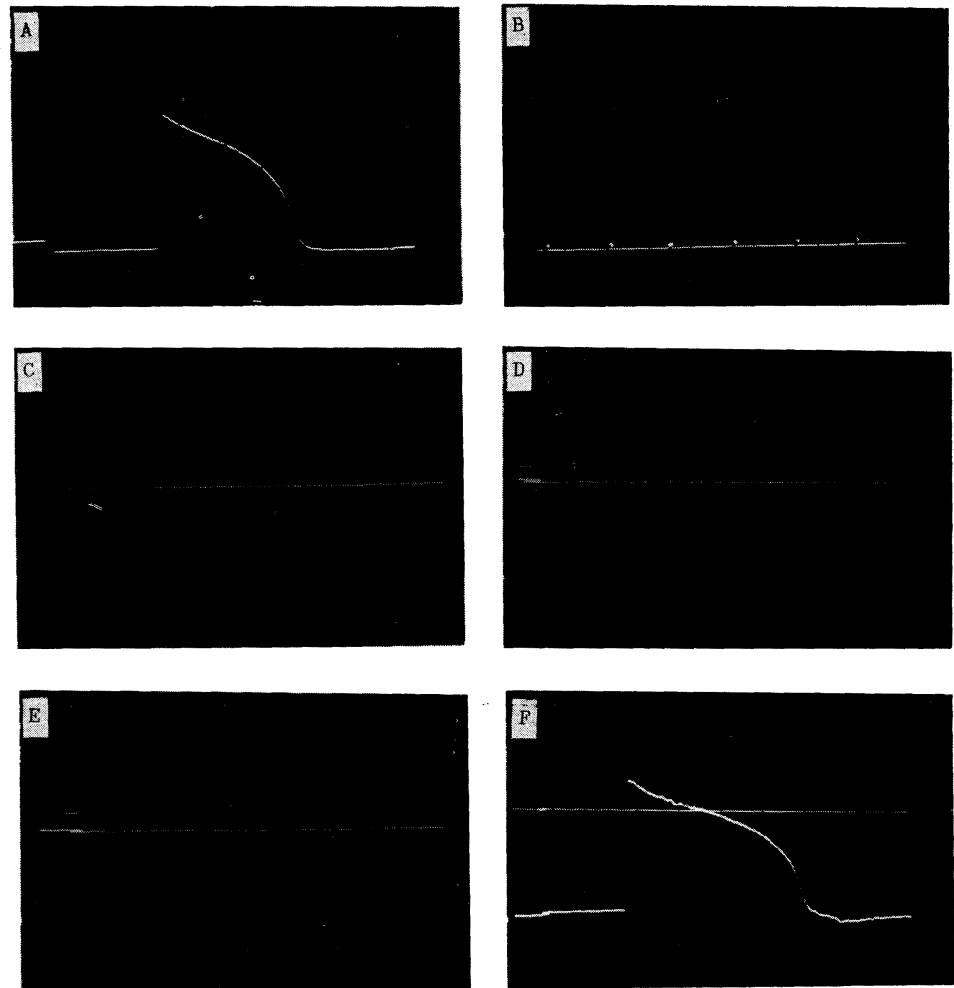

FIG. 5. Transmembrane potentials of cardiac ventricular cells recorded with microelectrode at various times after immersion in isotonic $\mathrm{K}$-Ringer solution with or without $50 \mathrm{mM}$ caffeine $\left(20^{\circ} \mathrm{C}\right)$. A. Normal Ringer solution. B. 2 cps; distance between the two lines shows $100 \mathrm{mV}$. C. $20 \mathrm{~min}$. after immersion in K-Ringer solution. D. $1 \mathrm{~min}$. after immersion in caffeine-K-Ringer solution. E. 3 min. after immersion in caffeine-K-Ringer solution. F. $15 \mathrm{~min}$. after replacing caffeine KRinger solution by normal Ringer solution.

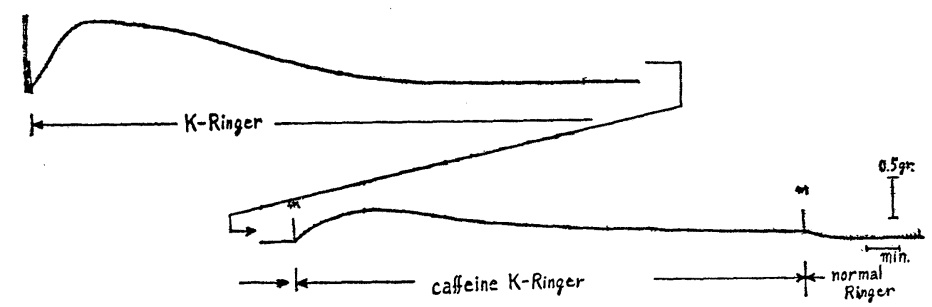

FIG. 6. Caffeine-contracture of the strip under the K-depolarized condition (K-Ringer solution). Contracture was evoked by addition of $50 \mathrm{mM}$ caffeine, after 20 minutes' immersion in K-Ringer solution. $\mathrm{m}$, mechanical artifact marking by withdrawal of bathing solution. 


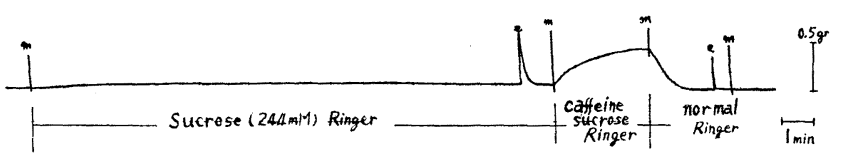

Fig. 7. Caffeine-contracture of the strip in sucrose-Ringer solution containing $50 \mathrm{mM}$ caffeine. e, tension of twitch induced by electric stimulus. $\mathrm{m}$, mechanical artifact marking by withdrawal of bathing solution.

FIG. 8. Effects of sucrose-Ringer solution and $50 \mathrm{mM}$ caffeinesucrose-Ringer solution on both action and resting potentials of the ventricular cells $\left(19^{\circ} \mathrm{C}\right)$. Abscissa, time after addition of caffeine; ordinate, transmembrane potential difference in $\mathrm{mV}$; solid circle, action potential; hollow circle, resting potential. For further explanation see in FIG. 3.

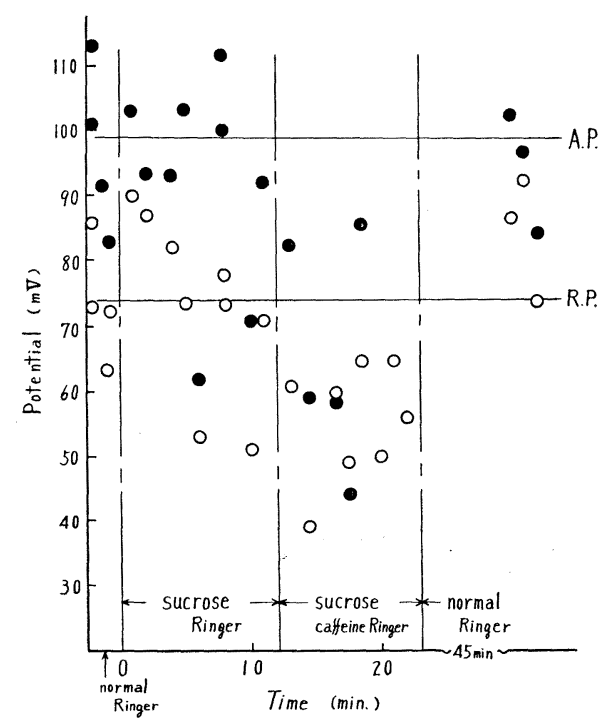

sucrose-Ringer solution, the contracture of the strip appeared (FIG. 7). The changes in the resting and action potentials of the strip in sucrose-Ringer solution and $50 \mathrm{mM}$ caffeine-sucrose-Ringer solution are shown in FIG. 8 . In sucrose-Ringer solution, these potentials tended to decrease with the lapse of time before the addition of caffeine, and the tendency was not accelerated by the addition of caffeine. In the above experiment, it was shown that the resting potential decreased slightly in sucrose-Ringer solution, so that the indispensable role of the membrane depolarization of cardiac cells in inducing the caffeine-contracture was not completely excluded.

Immersed in $50 \% \mathrm{~K}$-Ringer solution, the strip showed an evident depolarization as shown in FIG. 9. However, any contractures due to caffeine did not appear. This result may probably indicate that the depolarization of the membrane is not essential for the caffeine-contracture. In glucose-, choline chloride- and glycerine-Ringer solution, caffeine-contractures appeared similarly.

The results described above indicate that it is necessary to replace all or almost all sodium of Ringer solution by other cation or non-electrolyte in order to induce the contracture of the strip by caffeine. 

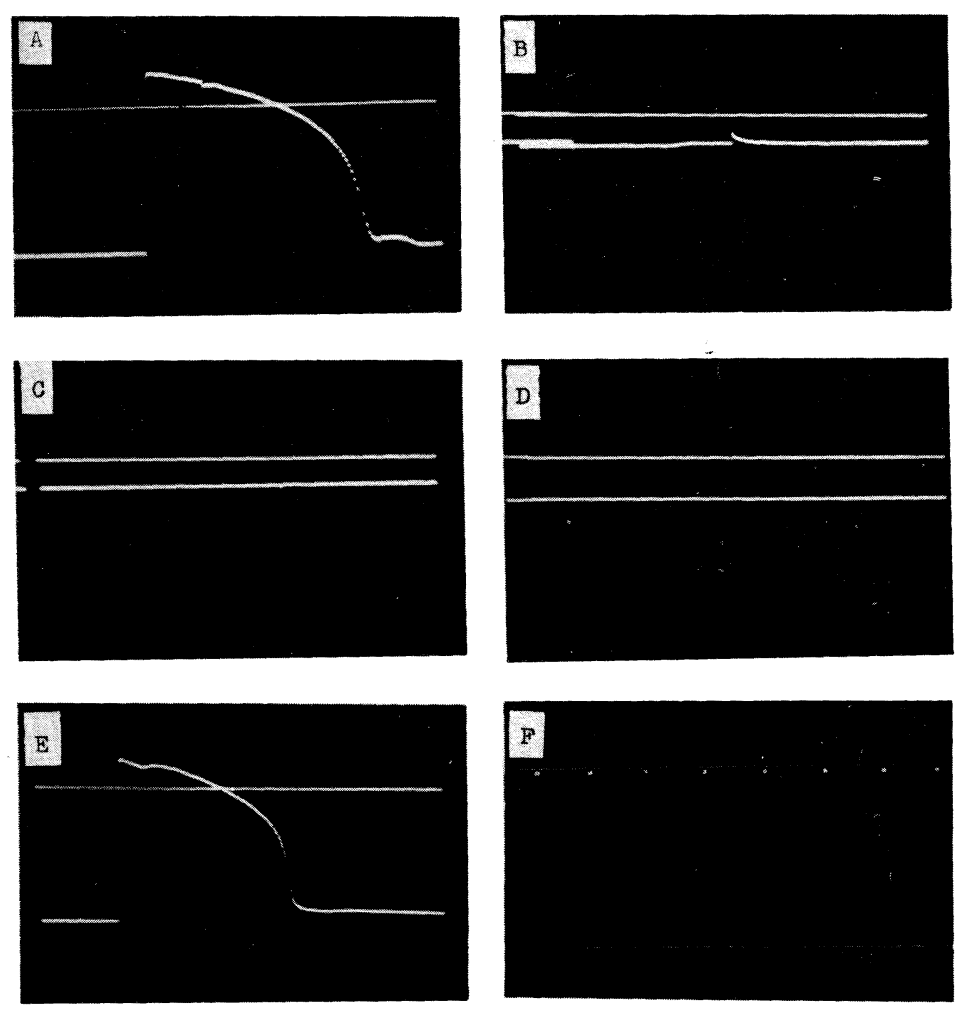

FIG. 9. Transmembrane potentials recorded in the strip of the ventricular cells which was serially immersed in $50 \% \mathrm{~K}$-Ringer solutions with or without $50 \mathrm{mM}$ caffeine $\left(17^{\circ} \mathrm{C}\right)$. A. In normal Ringer solution. B. 19 min. after immersion in 50\% K-Ringer solution. C. 1 min. after in $50 \% \mathrm{~K}$-Ringer solution containing $50 \mathrm{mM}$ caffeine. D. $2 \mathrm{~min}$. after immersion in $50 \% \mathrm{~K}$-Ringer solution, after removing from caffeine-50\% K-Ringer solution. E. $17 \mathrm{~min}$. after immersion in normal Ringer solution, after removing from $50 \%$ K-Ringer solution. F. $2 \mathrm{cps}$; distance between the two lines shows $100 \mathrm{mV}$.

5. Effects of chelating agents on the caffeine-contracture. The effects of calcium on the caffeine-contracture was examined by immersing the strip in the Ca-free K-Ringer solution containing $1 \mathrm{mM}$ EDTA. FIG. 10 shows the relations between the duration of the immersion in the $1 \mathrm{mM}$ EDTA solution and the maximum tension developed by the contracture of the strip. The tension decreased as the duration of the immersion was prolonged and no contracture was induced by caffeine at 20 minutes after immersion in the $1 \mathrm{mM}$ EDTA solution. Similar results were obtained in the experiment using $2 \mathrm{mM}$ sodium citrate, which also prevented the contracture within 20 minutes. The immersion of the strip in $2 \mathrm{mM}$ sodium oxalate for 20 minutes inhibited the contracture, though not completely. By immersing the strip in the Ca-free K-Ringer 
FIG. 10. Relationship between the removal of $\mathrm{Ca}$ and the caffeinecontracture of strip under K-depolarized condition. Ordinates, peak tension of the contracture. Abscissa, time after the treatment to remove $\mathrm{Ca}$ by immersion in $1 \mathrm{mM}$ EDTA-Ca-free K-Ringer solution.

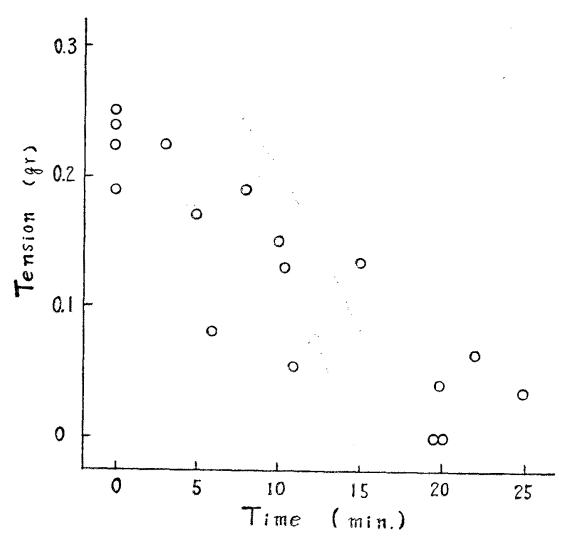

solution for 20 minutes, however, the caffeine-contracture similar to those seen in K-Ringer solution was induced. Thus, the effectivenesses of the chelating agents arrange themselves in the following order: EDTA $\gg$ sodium citrate $>$ sodium oxalate. This order coincides with that of the Ca-binding capacity ${ }^{17}$ of these agents. The results may suggest an active role of calcium in the induction of the contracture by caffeine.

6. Relaxation of the caffeine-contracture. In the K-Ringer solution, the contracture induced by caffeine was spontaneously relaxed and disappeared within about 20 minutes after immersion (FIG. 6). FIG. 11 shows the effect of the

FIG. 11. Three types of relaxation of caffeine-contracture under various conditions. The conditions were given when the tension of contracture reached the maximum, and the recordings were made on the same strip. $\times-\times$, relaxation in the presence of caffeine. $\Delta-\Delta$, relaxation initiated by removing caffeine from bathing solution. $\bigcirc-O$, relaxation in the presence of caffeine and $3 \mathrm{mM}$ EDTA.

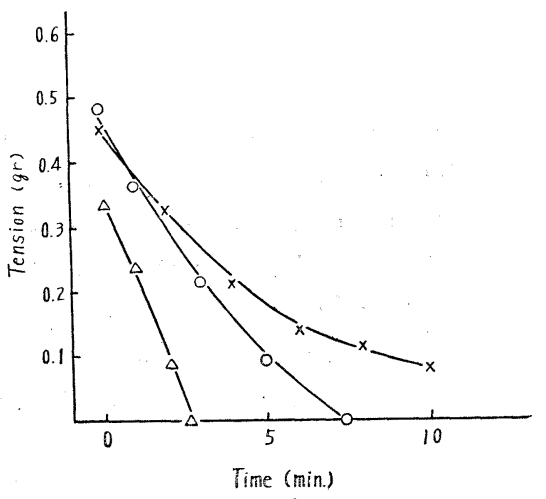

medium on the process of this relaxation. When caffeine was washed out from the strip showing the maximum contracture, a rapid relaxation occurred. A similar phenomenon was obtained by addition of $3 \mathrm{mM}$ EDTA. From these facts and the results derived from the experiment 5 , it would be concluded that calcium is indispensable for the induction and maintenance of the caffeinecontracture. This type of the action of calcium was reported by PAUSCHINGER ${ }^{18)}$ 


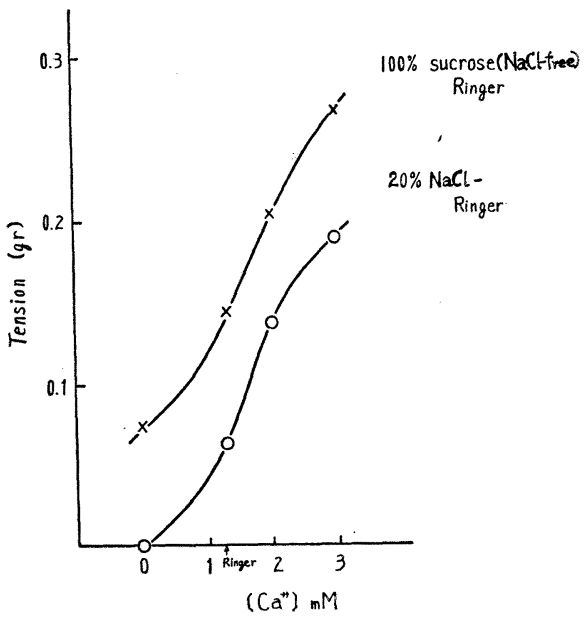

Fig. 12. Effects of $\mathrm{Ca}$ and $\mathrm{Na}$ concentrations on the maximum tension of caffeine-contracture. In $100 \%$ sucrose-Ringer solution, $\mathrm{NaCl}$ in normal Ringer solution was replaced by $244 \mathrm{mM}$ sucrose; in $20 \%$ $\mathrm{NaCl}$-Ringer solution, $80 \%$ of $\mathrm{NaCl}$ of normal Ringer solution was replaced by $195 \mathrm{mM}$ sucrose. Ringer on abscissa indicates the calcium concentration in normal 'Ringer' solution.

in the skeletal muscle.

7. Effects of the concentration of $\mathrm{Ca}$ and $\mathrm{Na}$ on the caffeine-contracture. The effect of calcium and sodium contained in the medium on the caffeine-contracture was studied. The contracture induced by caffeine was observed in sucroseRinger solutions containing various concentrations of calcium and sodium. The results are shown in FIG. 12. The contracture was easily induced by caffeine in the sucrose-Ringer solution containing a large amount of calcium, or lacking sodium.

\section{DISCUSSION}

In the present study, it was shown that the action of caffeine on the function of the cardiac ventricular muscle of the frog in Ringer solution depended on the concentration of caffeine and on the length of soaking time in the caffeine solution. The increase in the strength of the automatic contraction of the strip by caffeine at the low concentration (FIG. 2-A), may correspond to the enhancing effect of caffeine on twitch ${ }^{19)}$ in the skeletal muscle. As the concentration of caffeine increased, the strip showed arhythmia and finally the automatic pulsation was arrested ${ }^{20)}$, though the electrical excitability remained. This facts may suggest that caffeine mainly affected on the pace maker of the strip to change the automaticity of cardiac muscle. When the strip was treated with the higher concentration of caffeine for relatively long period, there occurred some changes in its action potential and in the contractility responsed to the electrical stimuli. This finding might participate in the analysis of the mechanism of intercellular propagation of excitation in the cardiac muscle. Recent evidence from electron microscopy has shown that the myocardium is not an anatomical syncytium ${ }^{21,22,23)}$. In addition, SPERELAXIS et $a .^{24)}$ and Goto 
AND TAMAI ${ }^{25)}$ have pointed out that the "fiber to fiber" junctional transmission may play an important role for impulse conduction in the heart. The present results suggest a toxic action of caffeine in the high concentration on this junctional transmission. The validity of this speculation may be evidenced by further investigation on this caffeine effect with the aid of the massive electrode, which can stimulate simultaneously all cells constituting the strip.

It was found in the present study that caffeine-contracture could be observed under some specific conditions. Namely, a high concentration of caffeine only in K-, choline chloride- or nonelectrolyte-Ringer solution induced the reversible contracture of the strip. Furthermore, it was shown that the existence of calcium, which was removed by chelating agents such as EDTA, was indispensable for the contracture. Therefore, it should be recalled that twitch or K-contracture in cardiac muscle was inhibited by sodium ions and required calcium ions ${ }^{16,26,27)}$. NIEDERGERKE AND LÜTTGAU ${ }^{27)}$ have proposed the hypothesis that the contraction of cardiac muscle is initiated by a negatively charged Ca-compound (an activator) which is moved from the surface into some deeper cellular compartment during depolarization of the cell membrane. They also suggested that sodium and calcium ions competed for the formation of activator. In the present study, it was shown that the depolarization of the membrane of the cardiac cell had no direct participation in inducing the caffeine-contracture of the strip, as the caffeine-contracture appeared both in K-Ringer solution and in nonelectrolyte-Ringer solution. If the mechanism of the contracture induced by caffeine is, as speculated by AxELSSON AND THESLEFF ${ }^{8)}$, the same as the ordinary contraction, these results would not support NIEDERGERKE's hypothesis. According to him, the removal of the membrane potential which acts as a barrier to the penetration of the activator, is indispensable for the activation of the contraction. Although the nature of the process linking the affecting site by caffeine to the contractile elements is not clear enough to draw any definite conclusion at present, it may be considered that caffeine acts on the superficial area of the cardiac cell, which is related to the $\mathrm{E}-\mathrm{C}$ coupling process. The process may be regulated by sodium and calcium concentration in the medium, and caffeine may induce the release of an activator without effecting on the electrical properties of the cell membrane. This hypothesis was supported by the fact that the contracture was inhibited by sodium in the medium and required calcium indispensably, and also by the fact that the effect of caffeine appeared very rapidly. It may be premature, however, to conclude that caffeine acts entirely at the cell membrane. In order to analyse the mechanism of caffeine-contracture it is important to study the effects of caffeine on the structure of sarcoplasmic reticulum ${ }^{28)}$ and on the relaxing factor ${ }^{29}$ of cardiac muscle.

The conditions for the caffeine-contracture of cardiac muscle found in the present study, were apparently different in some points from those shown in 
the skeletal muscle. Calcium is indispensable for caffeine-contracture of cardiac muscle, but not for that of skeletal muscle ${ }^{8,30)}$, although caffeine-contracture in cardiac and in skeletal muscle has no direct relation to the depolarization of membrane. The former fact may indicate an important difference in the process of $\mathrm{E}-\mathrm{C}$ coupling between the cardiac and the skeletal muscle. Recently, BIANCHI $^{31)}$ suggested a possible mechanism of the action of caffeine on the sartorius muscle of the frog. According to him, caffeine causes the release of calcium ions within the fiber. When this possibility was considered, the difference between the processes of E-C coupling occurred in the cardiac and the skeletal muscle may be due to the difference of the role of bound calcium ions within the cell.

\section{SUMMARY}

In order to clarify the mechanism of the excitation-contraction coupling of the cardiac muscle, the effect of caffeine on the cardiac ventricular strip of the frog was studied under various conditions and following results were obtained. 1. In normal Ringer solution, caffeine $(5-50 \mathrm{mM})$ did not cause the contracture of the strip.

Under the same condition, however, caffeine affected the automaticity and the contractility of the strip; a contractility increased at the low concentration (about $5-10 \mathrm{mM}$ of caffeine) and decreased at the high concentration (about 20-50 $\mathrm{mM}$ ), and the alternations of automaticity occurred arhythmia and arrest of pulsation. Even in the case of the arrest of pulsation, the mechanical responses to the electrical stimuli were observed.

2. The high concentration of caffeine $(50 \mathrm{mM})$ caused decrease of both resting potential and duration of plateau of the action potential, but these changes were recovered in the normal Ringer solution. This indicates that the effects of caffeine are perfectly reversible.

3. By the prolonged immersion in the high concentration of caffeine, the contraction by electrical stimuli was limited to a localized area.

4. One of the conditions for inducing caffeine-contracture is the deficiency of sodium in the bathing solution, that is, the contracture occurred in the Ringer solutions of which sodium was replaced by $\mathrm{KCl}$, choline chloride or nonelectrorytes (sucrose, glucose and glycerine). The other condition indispensable for inducing the contracture was the existence of calcium which could be removed by the application of chelating agent. The treatment by Ca-free medium was not sufficient enough to remove the calcium from the cell.

5. The grade of the contracture was dependent on the concentration of calcium and sodium contained in the Ringer solution; at the constant concentration of sodium, the grade was higher in the higher concentration of calcium; at the constant concentration of calcium, the grade was lower in the higher concen- 
tration of sodium.

From these results, the mechanism of the excitation-contraction coupling and the affected site by caffeine were discussed in comparison with the case of the skeletal muscle.

I am much indebted to Prof. Torao NAGAI for his criticism in the course of the work. Thanks are also due to Dr. Masahiro Fujino and other members of the laboratory for their help to the experiment.

\section{REFERENCES}

1) SAndow, A. Yale J. Biol. Med. 25 : 176 (1952).

2) Katz, B. Arch. Sci. Physiol. $3: 285$ (1949).

3) Kuffler, S. W. J. Neurophysiol. $9: 367$ (1946).

4) Sten-Knudsen, O. J. Physiol. 125: 396 (1954).

5) Huxley, A. F. Progr. Biophys. Biophys. Chem. $7: 255$ (1957).

6) Gelfan, S. Ann. Rev. Physiol. $20: 67$ (1958).

7) Mashima, H. Medicine of Japan in 1959 (in Japanese), 5, p. 333; Tokyo; General Assembly of the Japan Medicial Congress, (1959).

8) Axelsson, J. And Thesleff, S. Acta Physiol. scand. $44: 55$ (1958).

9) Matsumura, M. Juntendo Med. J. (in Japanese), $5: 265$ (1958).

10) Kotowski, H., Antoni, H. And Fleckenstern, A. Pflügers Arch. ges. Physiol. 270 : 85 (1959).

11) Howarth, J. V. J. Physiol. $144: 167$ (1958).

12) Woodbury, J. W. And Brady, A. J. Science 123: 100 (1956).

13) Furukawa, T. Guide to The Microelectrode Technique (in Japanese) 1st ed., p. 107; Tokyo; Kinpodo Publishing Co., Ltd. (1957).

14) Fleckenstein, A. Der Kalium-Natrium Austausch als Energieprinzip in Muskel und Nerv, p. 80 ; Berlin; Springer-Verlag. (1955).

15) Daly, I. B. and Clark, A. J. J. Physiol. $54: 367$ (1921).

16) Niedergerke, R. ANd Lüttgau, H. C. Nature 179: 1066 (1957).

17) Martell, A.E. Chemistry of the Muscle Chelate Compound, p. 445; New York; Prentice-Hall, Inc. (1952).

18) Pauschinger, P. Pflügers Arch. ges. Physiol. $272: 254$ (1961).

19) Ritchie, J. M. J. Physiol. $126: 155$ (1954).

20) Chenery, R. H. J. Pharmacol. Exper. Thera. $54: 213$ (1935).

21) Suöstrand, S. F. And Andersson, E. Experimentia 10:369 (1954).

22) Moore, D. H. And Ruska, H. J. Biophys. and Biochem. Cytol. $3: 261$ (1957).

23) Faucett, D. W. And Selby, C. C. J. Biophys. and Biochem. Cytol. $4: 63$ (1958).

24) Sperelaxis, N., Hoshiko, T., Keller, F. R. JR. and Bern, R. M. Am. J. Physiol. $198: 135$ (1960).

25) Goto, M. And Tamai, T. Modern Aspects of The Electrophysiology of Involuntary Muscle, (in Japanese) 1st ed., p. 166; Tokyo; Kinpodo Publishing Co., Ltd. (1960).

26) Lüttgau, H. C. And Niedergerke, R. J. Physiol. 143 : 486 (1958).

27) Niedergerke, R. Expermentia 15: 128 (1959).

28) Porter, K. R. And Palade, G. E. J. Biophys. and Biochem. Cytol. 3 : 269 (1957).

29) Briggs, F. N. And Fuchs, F. Biochim. Biophys. Acta $42: 519$ (1960).

30) Frank, G. B. J. Physiol. $151: 518$ (1960).

31) Bianchi, C. P. J. Gen. Physiol. $44: 845$ (1961).

32) Brady, A. J. And Woodbury, J. W. J. Physiol. $154: 385$ (1960). 